\title{
Occupational and environmental risk factors for respiratory symptoms in rural Beijing, China
}

\author{
L-X. Zhang*, D.A. Enarson", G-X. He*, B. Li*, M. Chan-Yeung
}

Occupational and environmental risk factors for respiratory symptoms in rural Beijing, China. L-X. Zhang, D.A. Enarson, G-X. He, B. Li, M. Chan-Yeung. C ERS Journals Ltd 2002

ABSTRACT: The aim of the present study was to determine the effects of occupational and environmental exposure on respiratory symptoms in adults in rural Beijing, China.

Thirty randomly selected villages in the counties of Shunyi and Tongxian, $50 \mathrm{~km}$ north and east, respectively, of the city of Beijing, China, participated in this study. Village doctors interviewed all residents aged $\geqslant 15$ yrs and completed the International Union Against Tuberculosis and Lung Disease Questionnaire on Bronchial Symptoms translated into Chinese with added questions on smoking and occupational and environmental exposure.

Of the eligible population, 22,528 adults $(98 \%)$ took part. The prevalence of all respiratory symptoms, i.e. asthma-like symptoms, asthma attacks in the last 12 months, chronic cough and chronic phlegm, was low. Significant determinants for respiratory symptoms were age, sex, smoking and county of residence. A dose-dependent relationship was found between cumulative cigarette consumption and prevalence of respiratory symptoms. After adjusting for these variables, exposure to insecticides and fertilisers significantly increased the risk of most of the respiratory symptoms, whereas exposure to indoor air pollution from domestic fuels did not.

Exposure to chemicals such as insecticides and fertilisers contributed independently to the risk of respiratory symptoms in rural Beijing, China. Eur Respir J 2002; 20: 1525-1531.
*Beijing Tuberculosis Control Research Institute, Beijing, China. "International Union Against Tuberculosis and Lung Diseases, Paris, France. Occupational and Environmental Lung Diseases Unit, University of British Columbia, Vancouver, BC, Canada.

Correspondence: M. Chan-Yeung, Dept of Medicine, The University of Hong Kong, 4/F Professorial Block, Queen Mary Hospital, Hong Kong, SAR, China.

Fax: 85228551143

E-mail: mmwchan@hkucc.hku.hk

Keywords: Environmental exposure respiratory symptoms rural China

Received: April 62002

Accepted after revision: July 52002
Cor pulmonale is the second leading cause of death in China and mortality rates for this condition are reported to be approximately equal in males and females despite the low prevalence of tobacco smoking among females [1]. The effect of cigarette smoking on lung function has been found to be considerably less among residents of China compared with those of Western countries [2]. Although this may be due to lower daily cigarette consumption in China or ethnic differences, the possibility that other risk factors, such as exposure to outdoor or indoor air pollution [3-5] or occupational pollutants [6, 7], may also be responsible for chronic obstructive lung disease and cor pulmonale must be critically assessed.

A survey has been carried out on adults in randomly selected villages in two rural counties of the municipality of Beijing, China [8], using the International Union Against Tuberculosis and Lung Disease (IUATLD) Questionnaire on Bronchial Symptoms [9]. A very low prevalence of asthma-like symptoms and self-reported asthma in the previous 12 months was found [8]. In the present report, the relationship of occupational and environmental exposure to chemical, insecticide, fertilisers and emissions from domestic fuel to asthma symptoms, self-reported asthma and chronic respiratory symptoms in these rural communities is examined.
Methods

\section{Study design}

A cross-sectional survey was carried out in 30 villages randomly selected from two rural counties, Shunyi and Tongxian, $50 \mathrm{~km}$ north and east, respectively, of the city of Beijing, China, and within the municipality of Beijing.

\section{Questionnaire}

The village doctor visited every household in the village and every individual aged $\geqslant 15$ yrs was invited to take part in the study. The doctor conducted an interview using a Chinese translation of the IUATLD questionnaire on bronchial symptoms [9] with added questions on chronic respiratory symptoms from the American Thoracic Society Division of Lung Disease questionnaire [10]. In addition, there were questions on tobacco smoking and environmental and occupational exposure to dust, chemicals, insecticides, fertilisers and other substances. The questionnaire was translated into Chinese and the first draft back-translated into English. Discrepancies between the original English form and first draft Chinese 
back-translation were reviewed, and a second translation carried out. This was again back-translated into English. It was after the third translation that equivalence was reached. The Chinese words for cough, wheeze, chest tightness, dyspnoea and phlegm used in the translation were the same as those used in a Chinese translation of the International Study of Asthma and Allergy in Children (ISAAC) questionnaire, the translation of which has been validated previously [11].

A training workshop was organised before the survey in order to instruct the village doctors on how to complete the questionnaire.

The following questions were used in the analysis: wheeze: "Have you had wheezing or whistling in your chest in the last 12 months?"; chest tightness: "Have you woken up with a feeling of tightness in your chest in the last 12 months?"; nocturnal shortness of breath: "Have you been woken by an attack of shortness of breath in the last 12 months?"; nocturnal cough: "Have you been woken by an attack of coughing in the last 12 months?"; asthma attack: "Have you had an attack of asthma in the last 12 months?"; asthma medication: "Are you currently taking any medication (including inhalers, aerosols or tablets) for asthma?"; chronic cough: "Do you usually have cough first thing in the morning or during the day?" and "Do you cough like this for as much as three months each year?"; chronic phlegm: "Do you usually have phlegm first thing in the morning or during the day?" and "Do you bring up phlegm like this for as much as three months each year?". Current smokers were defined as those who were still smoking within 1 month of the study, nonsmokers were lifelong nonsmokers and exsmokers the remainder.

Occupational and environmental exposure were considered present if there was a positive response to the following questions: "Have you ever been exposed regularly to chemicals at work? If yes, to insecticides?, to fertilizers? or other chemicals?".

As many families used a combination of materials for fuel, exposure to fuels was classified according to the estimated level of pollution, from the lowest to highest, as follows: gas, electricity and oil; gas and coal; gas, coal and wood; and any of the above plus cornstalk and manure.

\section{Analysis}

The effects of various exposures (cigarette smoking, insecticide, pesticide and fertiliser, and various types of fuel) on respiratory symptoms were tested in univariate analyses, initially using Chi-squared tests. Logistic regression analysis was then used to examine the effects of these exposures on respiratory symptoms adjusted for age, sex, smoking and county of residence, as well as interaction between smoking and exposure to chemicals.

\section{Ethics}

The Ethics Committee of the University of British Columbia approved the study. Those eligible for the study were asked to give written consent, after a full explanation of study procedures was presented. All records were kept confidentially and released to a third party only on written request from the participant. Participants were informed of any abnormalities warranting further investigations and these investigations were carried out in the county hospital. Those found to have asthma were offered treatment for their illness.

\section{Results}

A total of 22,528 males and females aged $\geqslant 15 \mathrm{yrs}$, representing $98 \%$ of all eligible subjects in 30 villages in the two rural counties in the municipality of Beijing, took part in the present study. The first county, Shunyi, has 7,442 and the second county, Tongxian, 15,119 residents in the above age group. The residents of the two counties were different in their age distribution, the proportion exposed to chemicals, insecticides and fertiliser at work, and their exposure to emissions from the types of domestic fuel used. There were no significant differences in the smoking habits of the residents of the two counties (table 1).

When all subjects from the two counties were analysed together, significant differences in the age distribution between males and females were found; more males were found in the younger age groups and more females in the older age groups. In addition, males and females differed in their smoking habits; only $4 \%$ of females but $55 \%$ of males were smokers. A significantly higher proportion of males were exposed regularly to chemicals at work compared with females (19.7 versus $16.0 \%$ ), but there were no differences in the proportion exposed to insecticides and fertilisers at work.

Table 1.-Characteristics of study subjects

\begin{tabular}{lccc}
\hline & Shunyi & Tongxian & Total \\
\hline $\begin{array}{l}\text { Subjects n } \\
\text { Sex }\end{array}$ & 7425 & 15103 & 22528 \\
$\quad$ Male & $3583(48.3)$ & $7381(48.9)$ & $10978(48.7)$ \\
Age group* & & & \\
$\quad<30$ yrs & $1614(21.7)$ & $3735(24.7)$ & $5349(23.7)$ \\
$30-49$ yrs & $3720(50.1)$ & $7003(46.4)$ & $10723(47.6)$ \\
$\quad>50$ yrs & $2091(28.2)$ & $4365(28.9)$ & $4365(28.9)$ \\
Smoking & & & \\
$\quad$ Nonsmokers & $5199(70.0)$ & $10521(69.6)$ & $15711(69.7)$ \\
$\quad$ Exsmokers & $104(1.4)$ & $176(1.2)$ & $280(1.2)$ \\
$\quad$ Current smokers & $2122(28.6)$ & $4415(29.2)$ & $6537(29.0)$ \\
Exposure & & & \\
$\quad$ Any chemical* & $600(8.1)$ & $3418(22.6)$ & $4018(17.8)$ \\
Insecticide* & $64(0.9)$ & $642(4.2)$ & $706(3.1)$ \\
$\quad$ Fertiliser* & $253(3.4)$ & $2992(19.8)$ & $3245(14.4)$ \\
Fuel & & & \\
$\quad$ Gas* & $5547(74.7)$ & $12243(81.1)$ & $17790(79.0)$ \\
Coal* & $5986(80.6)$ & $12001(79.5)$ & $17987(79.8)$ \\
$\quad$ Wood* & $1401(18.9)$ & $2995(19.8)$ & $4396(19.5)$ \\
$\quad$ Cornstalk* & $416(5.6)$ & $3867(25.6)$ & $4283(19.0)$ \\
$\quad$ Manure* & $1(0.0)$ & $13(0.1)$ & $14(0.1)$ \\
\hline
\end{tabular}

Data are presented as $\mathrm{n}(\%)$. *: $\mathrm{p}<0.05$ for male versus female prevalence (Chi-squared test). 

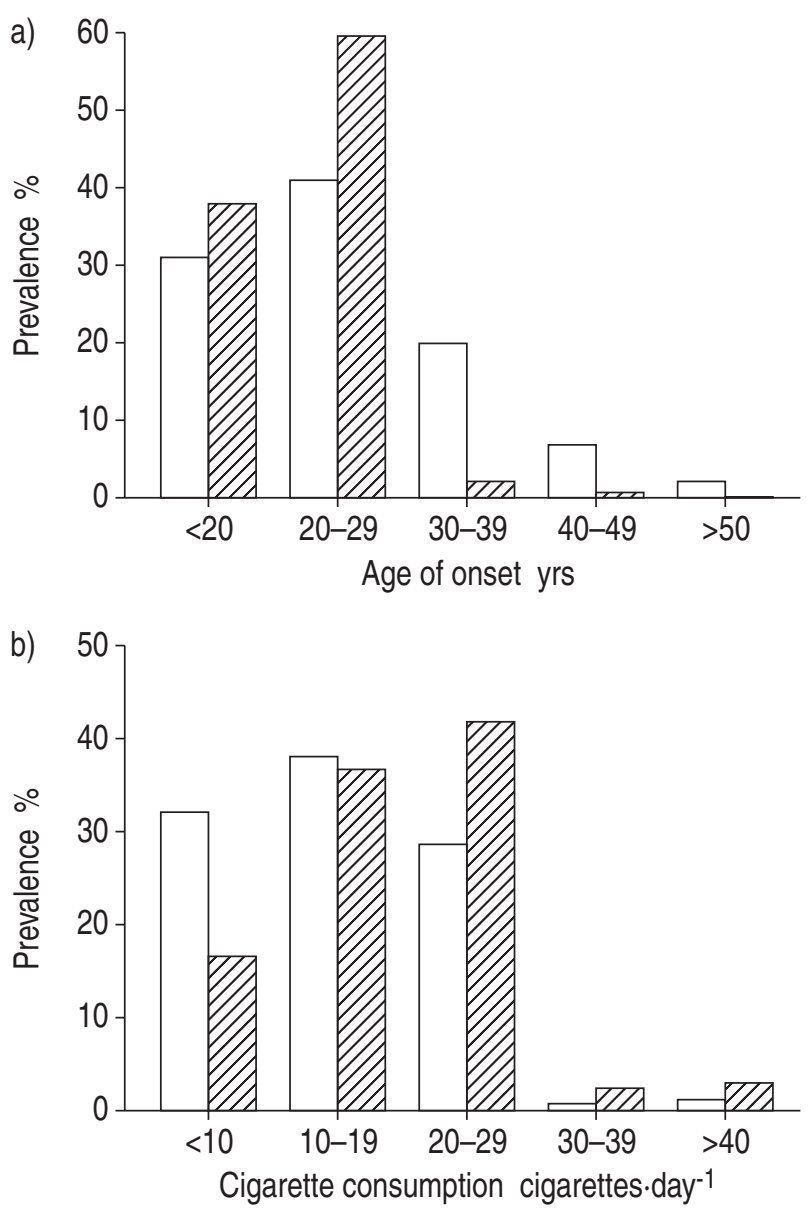

Fig. 1.-Comparison of a) age of onset of smoking and b) daily cigarette consumption in females $(\square)$ and males $(\mathbb{Z})$.

The age of onset of smoking and mean daily cigarette consumption for females and males are shown in figure 1 . Among current smokers, $31 \%$ of females and $38 \%$ of males had started smoking before the age of 20 yrs. Among smoking females, 32\% smoked $<10$ cigarettes $\cdot$ day $^{-1}$ and $\sim 30 \%>20$ cigarettes $\cdot$ day $^{-1}$. Among smoking males, $17 \%$ smoked $<10$ cigarettes $\cdot$ day $^{-1}$, whereas $47 \%$ smoked $>20$ cigarettes $\cdot$ day $^{-1}$.
Table 2 shows the prevalence of respiratory symptoms, self-reported asthma attacks and use of asthma medications for each category of smoking habit. There were few exsmokers in the study, but they showed the highest prevalence of each of the respiratory symptoms. There was a dose-dependent trend in the association between cumulative cigarette consumption and prevalence of respiratory symptoms; the greater the cigarette consumption the higher the prevalence of respiratory symptoms. Compared with the current smokers, the exsmokers were significantly older $(43.6 \pm 13.9$ versus $56.3 \pm 14.4 \mathrm{yrs})$ and had smoked a significantly greater amount (17.6 \pm 15.1 versus $21.6 \pm 17.5$ pack-yrs). Residents of Tongxian showed a higher prevalence of all respiratory symptoms compared to those of Shunyi irrespective of smoking habits (data not shown).

Table 3 shows the prevalence of respiratory symptoms, self-reported asthma attacks and use of antiasthma medications according to reported exposure to materials in the workplace. Exposure to any chemical, insecticide or fertiliser at work was consistently associated with a significantly higher prevalence of all symptoms compared with those without such exposure. The prevalence of chronic cough and phlegm among those exposed to insecticides was higher in males than in females (6.1 and 6.7\% versus 4.4 and $3.8 \%$, respectively). Among those exposed to fertilisers, the prevalence of wheeze, awakening with shortness of breath and asthma attacks in the past 12 months was higher in females compared with males $(4.4,2.6$ and $3.8 \%$ versus $3.1,1.6$ and $2.3 \%$, respectively).

The use of cornstalk and manure as fuel was associated with a higher prevalence of respiratory symptoms compared to other types of fuel (table 4).

Table 5 shows that sex, age, smoking and county of residence were significant determinants of respiratory symptoms. Females showed a significantly higher risk of asthma and asthma-like symptoms but not chronic cough and phlegm. The risk of each of the respiratory symptoms increased significantly with age. Residents of Tongxian demonstrated a significantly higher risk of each of the respiratory symptoms than those of Shunyi. Exsmokers had the highest risk of each of the

Table 2. - Prevalence of chest symptoms by smoking habit

\begin{tabular}{lccccccc}
\hline & Nonsmoker & Exsmoker & \multicolumn{2}{c}{ Current smoker } & Total \\
\cline { 3 - 6 } & & & & $\begin{array}{c}<10 \\
\text { pack-yrs }\end{array}$ & $\begin{array}{c}10-19 \\
\text { pack-yrs }\end{array}$ & $\begin{array}{c}20-29 \\
\text { pack-yrs }\end{array}$ & $\begin{array}{c}>30 \\
\text { pack-yrs }\end{array}$ \\
\hline Subjects n & 15734 & 281 & 2300 & 1904 & 1216 & 1126 & 22561 \\
Wheeze & $2.0(1.9-2.1)$ & $22.1(20.0-24.1)$ & $1.5(1.3-1.7)$ & $2.2(1.9-2.5)$ & $4.5(4.0-5.0)$ & $7.5(6.9-8.2)$ & $2.6(2.5-2.7)$ \\
Chest tightness & $1.5(1.4-1.6)$ & $13.9(12.1-15.6)$ & $0.8(0.7-1.0)$ & $1.5(1.3-1.8)$ & $2.6(2.2-3.0)$ & $3.2(2.7-3.6)$ & $1.7(1.7-1.8)$ \\
Nocturnal SOB & $1.0(1.0-1.1)$ & $14.2(12.4-16.0)$ & $0.9(0.7-1.0)$ & $1.0(0.8-1.2)$ & $1.6(1.3-2.0)$ & $3.9(3.4-4.4)$ & $1.4(1.3-1.4)$ \\
Nocturnal cough & $2.0(1.9-2.0)$ & $18.5(16.6-20.4)$ & $1.8(1.6-2.0)$ & $2.5(2.2-2.8)$ & $4.4(3.9-4.8)$ & $7.4(6.8-8.0)$ & $2.6(2.5-2.7)$ \\
Asthma attack & $1.5(1.4-1.6)$ & $18.5(16.6-20.4)$ & $1.0(0.9-1.2)$ & $1.1(0.9-1.3)$ & $2.7(2.3-3.1)$ & $5.1(4.5-5.6)$ & $1.9(1.8-1.9)$ \\
Asthma & $1.1(1.0-1.1)$ & $14.9(13.1-16.7)$ & $0.9(0.7-1.0)$ & $0.7(0.6-0.9)$ & $2.1(1.7-2.4)$ & $3.7(3.3-4.2)$ & $1.4(1.3-1.4)$ \\
$\quad$ medication & & & & & & & \\
Chronic cough & $1.0(1.0-1.1)$ & $16.7(14.8-18.5)$ & $1.6(1.4-1.8)$ & $1.8(1.6-2.1)$ & $4.3(3.8-4.7)$ & $8.4(7.8-9.1)$ & $1.9(1.8-2.0)$ \\
Chronic phlegm & $1.0(1.0-1.1)$ & $15.7(13.8-17.4)$ & $1.5(1.3-1.7)$ & $1.9(1.6-2.1)$ & $4.4(3.9-4.8)$ & $8.4(7.8-9.1)$ & $1.9(1.8-1.9)$ \\
\hline
\end{tabular}

Data are presented as percentages ( $95 \%$ confidence interval). SOB: shortness of breath. 
Table 3. - Prevalence of symptoms by exposure to any chemical, insecticide, and fertiliser at work

\begin{tabular}{|c|c|c|c|c|c|c|}
\hline & \multicolumn{2}{|c|}{ Any chemical } & \multicolumn{2}{|c|}{ Insecticide } & \multicolumn{2}{|c|}{ Fertiliser } \\
\hline & Yes & No & Yes & No & Yes & No \\
\hline Subjects $n$ & 4020 & 18541 & 706 & 21855 & 3247 & 19314 \\
\hline Wheeze & $3.5(3.3-3.7)$ & $2.4(2.3-2.5)$ & $5.8(5.1-6.5)$ & $2.5(2.4-2.6)$ & $3.7(3.5-4.0)$ & $2.4(2.3-2.5)$ \\
\hline Chest tightness & $3.0(2.8-3.2)$ & $1.5(1.4-1.5)$ & $4.0(3.3-4.6)$ & $1.7(1.6-1.7)$ & $3.4(3.2-3.7)$ & $1.4(1.4-1.5)$ \\
\hline Nocturnal SOB & $1.9(1.7-2.1)$ & $1.2(1.2-1.3)$ & $3.4(2.8-4.0)$ & $1.3(1.2-1.3)$ & $2.1(1.9-2.7)$ & $1.2(1.2-1.3)$ \\
\hline Nocturnal cough & $4.0(3.8-4.2)$ & $2.3(2.2-2.4)$ & $6.9(6.1-7.7)$ & $2.4(2.4-2.5)$ & $4.3(4.0-4.6)$ & $2.3(2.2-2.4)$ \\
\hline Asthma attack & $2.8(2.6-3.0)$ & $1.7(1.6-1.7)$ & $5.1(4.4-5.8)$ & $1.8(1.7-1.8)$ & $3.0(2.8-3.3)$ & $1.7(1.6-1.7)$ \\
\hline Asthma medication & $2.0(1.8-2.1)$ & $1.3(1.2-1.3)$ & $3.3(2.7-3.8)$ & $1.3(1.3-1.4)$ & $2.1(1.9-2.3)$ & $1.3(1.2-1.3)$ \\
\hline Chronic cough & $2.7(2.5-2.9)$ & $1.7(1.7-1.8)$ & $5.2(4.5-5.9)$ & $1.8(1.7-1.9)$ & $3.0(2.7-3.2)$ & $1.7(1.7-1.8)$ \\
\hline Chronic phlegm & $3.0(2.8-3.2)$ & $1.6(1.6-1.7)$ & $5.2(4.5-5.9)$ & $1.8(1.7-1.8)$ & $3.1(2.9-3.3)$ & $1.7(1.6-1.7)$ \\
\hline
\end{tabular}

Data are presented as percentages $(95 \%$ confidence interval). SOB: shortness of breath.

Table 4. - Prevalence of chest symptoms by fuel exposure

\begin{tabular}{llllrl}
\hline & $\begin{array}{c}\text { Gas+electricity+ } \\
\text { oil }\end{array}$ & Gas+coal & $\begin{array}{c}\text { Gas+coal+ } \\
\text { wood }\end{array}$ & $\begin{array}{c}\text { Any other fuel+ } \\
\text { cornstalk or manure }\end{array}$ & Total \\
\hline Wheeze & $2.1(1.9-2.4)$ & $1.9(1.8-2.0)$ & $2.8(2.5-3.0)$ & $2.9(2.7-3.1)$ & $2.3(2.2-2.4)$ \\
Chest tightness & $1.2(1.0-1.4)$ & $1.1(1.0-1.2)$ & $2.3(2.1-2.5)$ & $2.4(2.2-2.6)$ & $1.6(1.5-1.6)$ \\
Nocturnal SOB & $1.1(0.9-0.3)$ & $1.0(0.9-1.1)$ & $1.4(1.2-1.5)$ & $1.7(1.5-1.9)$ & $1.2(1.2-1.3)$ \\
Nocturnal cough & $2.3(2.0-2.6)$ & $1.8(1.7-1.9)$ & $2.3(2.1-2.5)$ & $3.4(3.2-3.6)$ & $2.3(2.2-2.3)$ \\
Asthma attack & $1.6(1.3-1.8)$ & $1.6(1.5-1.7)$ & $2.1(1.9-2.3)$ & $2.5(2.4-2.7)$ & $1.9(1.8-1.9)$ \\
Asthma medication & $1.0(0.8-1.2)$ & $1.2(1.1-1.3)$ & $1.7(1.5-1.9)$ & $1.7(1.6-1.9)$ & $1.4(1.3-1.4)$ \\
Chronic cough & $1.4(1.1-1.6)$ & $1.2(1.2-1.3)$ & $1.9(1.7-2.1)$ & $2.5(2.3-2.7)$ & $1.6(1.6-1.7)$ \\
Chronic phlegm & $1.1(0.9-1.3)$ & $1.2(1.1-1.3)$ & $1.9(1.7-2.0)$ & $2.6(2.4-2.7)$ & $1.6(1.5-1.6)$ \\
\hline
\end{tabular}

Data are presented as percentages ( $95 \%$ confidence interval). SOB: shortness of breath.

respiratory symptoms. There was a dose-dependent relationship between cumulative cigarette consumption and risk of having various respiratory symptoms. The risk for asthma and asthma-like symptoms increased significantly only for smokers of $>20$ packyrs, whereas the risk for chronic cough and phlegm increased significantly even for those who smoked $<10$ pack-yrs. After adjusting for the above factors, regular exposure to insecticide and fertiliser at work remained significantly associated with a high risk of almost all symptoms except for the association of exposure to insecticide with chest tightness and of exposure to fertiliser with asthma attacks during the last 12 months and chronic cough. The association of the use of cornstalk/manure as fuel with an increase in risk of respiratory symptoms was no longer significant after adjustment for other factors. The use of wood as fuel carried a significantly higher risk of chest tightness and chronic cough. No interaction was found between smoking and exposure to any chemicals, insecticides and fertilisers in relation to respiratory symptoms.

The above analysis was repeated separately for males and females. The findings in relation to age, smoking and county of residence were similar to those obtained for the whole population. With regular exposure to insecticide at work, males showed significantly higher risks of each of the respiratory symptoms with the exception of chest tightness, whereas females showed significantly higher risks of only chronic cough and chronic phlegm. With regular exposure to fertiliser, females had significantly higher risks of each of the respiratory symptoms with the exception of chronic cough, whereas males had significantly higher risks only of chest tightness and nocturnal cough (data not shown).

\section{Discussion}

In the present study, the relationship of occupational and environmental exposure to asthma symptoms, selfreported asthma and chronic respiratory symptoms, adjusted for the effect of age, sex and smoking, was examined. It was found that the prevalence of chronic cough and phlegm was low in the study population in rural Beijing, compared with that reported in industrialised countries that took part in the European Community Respiratory Health Survey and in the USA [12, 13]. BUIST et al. [2] additionally reported a lesser deficit in lung function associated with smoking among residents of China than that reported in Western countries. It has been postulated that the lesser effect in the Chinese may be due to a smaller amount being smoked [14]. This deficit in degree of functional impairment might also be due to the later age of onset of smoking in China [14]. In the present study, there was no opportunity to measure lung function. However, the later age of onset of smoking in this rural population and the smaller amount smoked were confirmed; these may account for the lower prevalence of respiratory symptoms.

A low prevalence of asthma symptoms and self-reported asthma attacks, and a much less frequent use of medication for asthma in rural Beijing than 
Table 5. - Effect of exposure to chemicals and various types of fuel on selected respiratory symptoms: multiple logistic regression analysis adjusted for age, sex, smoking and county of residence

\begin{tabular}{|c|c|c|c|c|c|c|}
\hline & Wheeze & $\begin{array}{l}\text { Chest } \\
\text { tightness }\end{array}$ & $\begin{array}{l}\text { Nocturnal } \\
\text { cough }\end{array}$ & Asthma attack & $\begin{array}{l}\text { Chronic } \\
\text { cough }\end{array}$ & $\begin{array}{l}\text { Chronic } \\
\text { phlegm }\end{array}$ \\
\hline \multicolumn{7}{|l|}{ Sex } \\
\hline Female & $\begin{array}{c}1.8 \\
(1.4-2.3)^{* * *}\end{array}$ & $\begin{array}{c}1.4 \\
(1.1-1.8)^{*}\end{array}$ & $\begin{array}{c}1.6 \\
(1.3-2.1)^{* * *}\end{array}$ & $\begin{array}{c}1.9 \\
(1.5-2.5)^{* * *}\end{array}$ & $\begin{array}{c}1.3 \\
(0.9-1.7)\end{array}$ & $\begin{array}{c}1.1 \\
(0.8-1.4)\end{array}$ \\
\hline \multicolumn{7}{|l|}{ Age yrs } \\
\hline $30-49$ & $\begin{array}{c}3.1 \\
(1.9-5.0)^{* * *}\end{array}$ & $\begin{array}{l}2.4 \\
(1.5-3.9)^{* * *}\end{array}$ & $\begin{array}{l}2.2 \\
(1.5-3.3)^{* * *}\end{array}$ & $\begin{array}{l}3.4 \\
(1.9-5.9)^{* * *}\end{array}$ & $\begin{array}{c}3.9 \\
(2.1-7.3)^{* * *}\end{array}$ & $\begin{array}{l}3.7 \\
(2.0-7.0) * * *\end{array}$ \\
\hline$>50$ & $\begin{array}{l}9.8 \\
(6.1-15.7)^{* * *}\end{array}$ & $\begin{array}{l}5.1 \\
(3.1-8.2)^{* * *}\end{array}$ & $\begin{array}{l}4.9 \\
(3.3-7.3)^{* * *}\end{array}$ & $\begin{array}{c}11.0 \\
(6.4-19.2)^{* * *}\end{array}$ & $\begin{array}{c}8.9 \\
(4.7-16.6)^{* * *}\end{array}$ & $\begin{array}{c}8.1 \\
(4.3-15.2)^{* * *}\end{array}$ \\
\hline \multicolumn{7}{|c|}{$\begin{array}{l}\text { Smoking } \\
\text { cigarettes } \cdot \text { day }^{-1}\end{array}$} \\
\hline Exsmoker & $\begin{array}{c}12.0 \\
(8.0-17.8)^{* * *}\end{array}$ & $\begin{array}{c}8.7 \\
(5.4-13.9)^{* * *}\end{array}$ & $\begin{array}{l}10.4 \\
(6.9-15.7)^{* * *}\end{array}$ & $\begin{array}{c}14.2 \\
(9.4-21.4)^{* * *}\end{array}$ & $\begin{array}{c}13.0 \\
(8.2-20.5)^{* * *}\end{array}$ & $\begin{array}{c}12.5 \\
(7.9-19.8)^{* * *}\end{array}$ \\
\hline$<10$ & $\begin{array}{c}1.5 \\
(0.96-2.3)\end{array}$ & $\begin{array}{c}0.67 \\
(0.36-1.2)\end{array}$ & $\begin{array}{c}1.3 \\
(0.85-2.0)\end{array}$ & $\begin{array}{c}1.6 \\
(0.98-2.5)\end{array}$ & $\begin{array}{c}2.0 \\
(1.3-3.2)^{* *}\end{array}$ & $\begin{array}{c}1.6 \\
(1.0-2.7)\end{array}$ \\
\hline $10-19$ & $\begin{array}{c}1.4 \\
(0.90-2.1)\end{array}$ & $\begin{array}{c}0.95 \\
(0.58-1.6)\end{array}$ & $\begin{array}{c}1.4 \\
(0.93-2.1)\end{array}$ & $\begin{array}{c}1.1 \\
(0.69-1.8)\end{array}$ & $\begin{array}{c}1.7 \\
(1.1-2.7)^{*}\end{array}$ & $\begin{array}{c}1.7 \\
(1.0-2.6)^{*}\end{array}$ \\
\hline $20-29$ & $\begin{array}{l}2.3 \\
(1.6-3.4)^{* * *}\end{array}$ & $\begin{array}{c}1.7 \\
(1.0-2.6)^{*}\end{array}$ & $\begin{array}{l}2.4 \\
(1.6-3.4)^{* * *}\end{array}$ & $\begin{array}{l}2.1 \\
(1.3-3.2)^{* * *}\end{array}$ & $\begin{array}{c}3.2 \\
(2.1-4.9)^{* * *}\end{array}$ & $\begin{array}{c}2.8 \\
(1.8-4.3)^{* * *}\end{array}$ \\
\hline$>30$ & $\begin{array}{c}3.1 \\
(2.2-4.2)^{* * *}\end{array}$ & $\begin{array}{c}1.6 \\
(1.0-2.5)^{*}\end{array}$ & $\begin{array}{c}3.1 \\
(2.2-4.4)^{* * *}\end{array}$ & $\begin{array}{c}2.8 \\
(1.9-4.0)^{* * *}\end{array}$ & $\begin{array}{l}5.6 \\
(3.9-8.0)^{* * *}\end{array}$ & $\begin{array}{c}5.0 \\
(3.5-7.2)^{* * *}\end{array}$ \\
\hline \multicolumn{7}{|l|}{ Exposure } \\
\hline Insecticide & $\begin{array}{c}1.8 \\
(1.2-2.6)^{* *}\end{array}$ & $\begin{array}{c}1.2 \\
(0.8-1.9)\end{array}$ & $\begin{array}{c}1.9 \\
(1.3-2.7)^{* * *}\end{array}$ & $\begin{array}{c}1.9 \\
(1.3-2.9)^{* *}\end{array}$ & $\begin{array}{l}2.2 \\
(1.4-3.3)^{* * *}\end{array}$ & $\begin{array}{l}2.0 \\
(1.3-3.0)^{* *}\end{array}$ \\
\hline Fertiliser & $\begin{array}{l}1.4 \\
(1.1-1.8)^{*}\end{array}$ & $\begin{array}{l}2.2 \\
(1.6-2.9)^{* * *}\end{array}$ & $\begin{array}{c}1.5 \\
(1.2-2.0)^{* * *}\end{array}$ & $\begin{array}{c}1.3 \\
(0.9-1.8)\end{array}$ & $\begin{array}{c}1.3 \\
(0.9-1.7)\end{array}$ & $\begin{array}{c}1.4 \\
(1.1-1.9)^{*}\end{array}$ \\
\hline \multicolumn{7}{|l|}{ Fuel } \\
\hline Coal & $0.98(0.7-1.4)$ & $1.0(0.6-1.5)$ & $0.89(0.6-1.2)$ & $1.1(0.7-1.6)$ & $0.98(0.6-1.5)$ & $1.2(0.7-1.9)$ \\
\hline Wood & $\begin{array}{c}1.3 \\
(0.9-1.9)\end{array}$ & $\begin{array}{c}1.9 \\
(1.2-3.0)^{* *}\end{array}$ & $\begin{array}{c}1.0 \\
(0.7-1.5)\end{array}$ & $\begin{array}{c}1.3 \\
(0.9-2.1)\end{array}$ & $\begin{array}{c}1.4 \\
(0.9-2.3)\end{array}$ & $\begin{array}{c}1.7 \\
(1.1-2.9)^{*}\end{array}$ \\
\hline Cornstalk & $\begin{array}{c}0.85 \\
(0.6-1.2)\end{array}$ & $\begin{array}{c}1.1 \\
(0.7-1.8)\end{array}$ & $\begin{array}{c}0.91 \\
(0.6-1.3)\end{array}$ & $\begin{array}{c}1.0 \\
(0.7-1.6)\end{array}$ & $\begin{array}{c}1.2 \\
(0.8-1.9)\end{array}$ & $\begin{array}{c}1.5 \\
(0.9-2.5)\end{array}$ \\
\hline \multicolumn{7}{|l|}{ County } \\
\hline Tongxian & $\begin{array}{c}1.6 \\
(1.3-2.0)^{* * *}\end{array}$ & $\begin{array}{l}2.0 \\
(1.4-2.7)^{* * *}\end{array}$ & $\begin{array}{l}2.1 \\
(1.6-2.8)^{* * *}\end{array}$ & $\begin{array}{c}1.4 \\
(1.1-1.8)^{* *}\end{array}$ & $\begin{array}{c}1.4 \\
(1.0-1.8)^{*}\end{array}$ & $\begin{array}{c}1.3 \\
(1.0-1.8)^{*}\end{array}$ \\
\hline
\end{tabular}

Data are presented as odds ratio $(95 \%$ confidence interval). Model: sex versus male; age versus $<30$ yrs; smoking versus nonsmoker; exposure: insecticide versus no insecticide and fertiliser versus no fertiliser; fuel: versus gas plus electricity plus oil; county versus Shunyi; Coal: gas plus coal; wood: gas plus coal plus wood; cornstalk: any fuel plus cornstalk or manure. *: $\mathrm{p}<0.05 ; * *: \mathrm{p}<0.01 ; * * *: \mathrm{p}<0.001$.

reported in industrialised countries, have previously been reported [8] and are similar to other observations from China [7]. A Chinese version of the ISAAC questionnaire for studying asthma and asthma-like symptoms in children has been validated [13]. The Chinese words used for wheeze and asthma in the present translation were exactly the same as those used in the Chinese ISAAC questionnaire. In the present survey, symptoms of asthma and chronic bronchitis were studied rather than doctor-diagnosed asthma and chronic bronchitis, thus, it is less likely that the low prevalence of asthma and bronchitis is due to failure of doctors to recognise the disease.

In the present study, it was found that females had a significantly higher risk of asthma-like symptoms and asthma attacks than males after adjusting for age, smoking, county of residence and other exposures. This finding has also been reported in other countries $[15,16]$, and the reason for the difference between the sexes is not known.

There is a dose-dependent relationship between cumulative cigarette consumption and prevalence of respiratory symptoms. The symptoms of chronic cough and phlegm increased significantly when cigarette consumption increased to $>10-19$ pack-yrs, whereas the prevalence of asthma-like symptoms increased significantly only in those who had smoked for >20-29 pack-yrs. The reason for this discrepancy in the effect of the amount smoked and type of respiratory symptoms is not clear. Exsmokers showed the highest prevalence of all symptoms, suggesting that they had had to give up smoking because of their symptoms. They were also older and had a greater cumulative cigarette consumption compared with the current smokers.

It was demonstrated that occupational exposure to insecticides was associated not only with increased asthma-like symptoms and asthma attacks, but also chronic respiratory symptoms. Approximately 4\% of villagers were exposed regularly to insecticides containing mostly organophosphate and pyrethrin; these chemicals have been shown to give rise to asthma [17-20]. A study of 1,939 farmers in Saskatchewan, Canada, found an increased risk of asthma associated 
with use of carbamate insecticides after adjusting for other confounders [21]. SALOME et al. [22] also reported that use of insecticide aerosols (containing pyrethrin or tetramethrin and others) triggered symptoms and a reduction in lung function in some people with asthma, and may increase airway hyperresponsiveness. Approximately $14 \%$ of the villagers in rural Beijing were occupationally exposed to fertilisers containing urea and exposure to fertilisers was associated with a significantly higher risk of respiratory symptoms. There have been no reports of association of fertiliser use with respiratory symptoms, although a higher prevalence of respiratory symptoms has been reported among workers in a chemical fertiliser plant, compared with unexposed controls [23], where high levels of exposure to ammonia probably account for the high prevalence of symptoms. The effect of fertiliser exposure on respiratory symptoms in females was greater than in males, whereas the effect of insecticide exposure was greater in males than in females. This could be related to differences in response between males and females to different exposures or differences in jobs related to females and males in the rural setting.

Air pollution due to the use of biomass fuel has been shown to be associated with chronic obstructive lung disease, especially in females [3, 4, 24, 25]. It was found that $\sim 19 \%$ of the families used wood or biomass (cornstalk/manure), but mostly as an additional rather than the principal fuel. The risk of various respiratory symptoms using wood or biomass was higher than using "cleaner" fuels but this association was not significant. Thus, indoor air pollution due to fuel combustion in the 30 villages around Beijing was not found to be independently associated with respiratory symptoms. This is in contrast to results reported by Xu et al. [7], who found significantly increased risks of wheeze associated with using wood/hay and coal as fuel in the rural communities in the province of Anhui in China. In the rural communities studied here, each household used a mixture of different materials as fuel and use of biomass was infrequent. This may be the reason for the discrepancy in findings in relation to use of fuels and respiratory symptoms.

There are other limitations to the present study. Other factors that might contribute to chronic respiratory symptoms in China, such as outdoor air pollution and respiratory infections, were not addressed. Pulmonary tuberculosis and bronchiectasis are common diseases that are associated with increased respiratory symptoms and chronic airflow obstruction in China. The types of fuel used were selfreported and levels of air pollution in the indoor environment were not measured.

In summary, age, sex and smoking were identified as important determinants of respiratory symptoms in rural Beijing, China. Occupational exposure to chemicals, such as insecticides and fertilisers, also partly accounts for the increase in risk of respiratory symptoms. the processing and analysis of data; D-H. Tu, C-S. Zhou, and Z-Q. Ma for organising the interviews; and the doctors in the villages who conducted the interviews.

\section{References}

1. Liu BQ, Peto R, Chen ZM, et al. Emerging tobacco hazards in China: 1. Retrospective proportion mortality study of one million deaths. BMJ 1998; 317: 1411-1422.

2. Buist AS, Vollmer WM, Wu Y, et al. Effects of cigarette smoking on lung function in four population samples in the People's Republic of China. Am J Respir Crit Care Med 1995; 151: 1393-1400.

3. Pandey MR. Domestic smoke pollution and chronic bronchitis in a rural community of the Hill Region of Nepal. Thorax 1984; 39: 337-339.

4. de Koning HW, Smith KR, Last JM. Biomass fuel combustion and health. Bull World Health Organ 1985; 63: 11-26.

5. Pope CA III, Xu X. Passive cigarette smoke, coal heating and respiratory symptoms of nonsmoking women in China. Environ Health Perspect 1993; 101: 314-316.

6. Becklake MR. Chronic airflow limitation: its relationship to work in dusty occupations. Chest 1988; 4: 608617.

7. $\mathrm{Xu} \mathrm{X}, \mathrm{Niu} \mathrm{T}$, Christiani DC, et al. Occupational and environmental risk factors for asthma in rural communities in China. Int J Occup Environ Health 1996; 2: 172-176.

8. Chan-Yeung M, Zhang L-X, Tu D-H, et al. The prevalence of asthma and asthma-like symptoms among adults in rural Beijing, China. Eur Respir $J$ 2002; 19: 853-858.

9. Burney PGJ, Laitinen LA, Perdrizet $\mathrm{S}$, et al. Validity and repeatability of the IUATLD (1984) Bronchial Symptoms Questionnaire: an international comparsion. Eur Respir J 1989; 2: 940-945.

10. Ferris B Jr. Recommended respiratory disease questionnaire for use with adults and children in epidemiology research. Am Rev Respir Dis 1978; 118: 7-53.

11. Lai CKW, Chan JKW, Chan A, et al. Comparison of the ISAAC video questionnaire (AVQ3.0) with the ISAAC written questionnaire for estimating asthma associated with bronchial hyperreactivity. Clin Exp Allergy 1997; 27: 540-545.

12. European Community Respiratory Health Survey. Variations in the prevalence of respiratory symptoms, self-reported asthma attacks, and the use of asthma medication in the European Community Respiratory Health Survey (ECHRS). Eur Respir J 1996; 9: 687695.

13. Centers for Disease Control and Prevention. Vital and Health Statistics: Current Estimates from the National Health Interview Survey, 1995. Dept of Health and Human Services Publication No. (PHS) 96-1527. Atlanta, GA, Centers for Disease Control and Prevention, 1998.

14. Yu JJ, Mattson ME, Boyd GM, et al. A comparison of smoking patterns in the People's Republic of China with the United States. An impending health catastrophe in the Middle Kingdom. JAMA 1990; 264: $1575-1579$. 
15. Omland O, Sigsgaard T, Hjort C, Pedersen OF, Miller MR. Lung status in young Danish rurals: the effect of farming exposure on asthma-like symptoms and lung function. Eur Respir J 1999; 13: 31-37.

16. Gold DR, Wang X, Wypij D, Speizer FE, Ware JH, Dockery DW. Effects of cigarette smoking on lung function in adolescent boys and girls. $N$ Engl $\mathrm{J} \mathrm{Med}$ 1996; 335: 931-937.

17. Deschamps D, Questel F, Baud FJ, Gervais P, Dally S. Persistent asthma after inhalation of organophosphate insecticide. Lancet 1994; 344: 1712.

18. Innes DF, Fuller BH, Berger GM. Low serum cholinesterase levels in rural workers exposed to organophosphate pesticide sprays. S Afr Med J 1990; 78: 581-583.

19. Vandenplas O, Delwiche JP, Auverdin J, Caroyer UM, Cangh FB. Asthma to tetramethrin. Allergy 2000; 55: 417-418.

20. Wax OM, Hoffman RS. Fatality associated with inhalation of a pyrethrin shampoo. J Toxicol Clin Toxicol 1994; 32: 457-460.
21. Senthilselvan A, McDuffie HH, Dosman JA. Association of asthma with use of pesticides. Results of a cross-sectional survey of farmers. Am Rev Respir Dis 1992; 146: 884-887.

22. Salome CM, Marks GB, Savides P, Xuan W, Woolcock AJ. The effects of insecticide aerosols on lung function, airway responsiveness and symptoms in asthmatic subjects. Eur Respir J 2000; 16: 38-43.

23. Ballal SG, Ali BA, Albar AA, Ahmed HO, Al-Hasan AY. Bronchial asthma in two chemical fertilizer producing factories in Eastern Saudi Arabia. Int J Tuberc Lung Dis 1998; 2: 330-335.

24. Perez-Padilla R, Regalado J, Vedal S, Park P, Chapela R, Selman M. Domestic biomass burning and chronic airflow obstruction in Mexican women: a case-control study. Am J Respir Crit Care Med 1996; 154: 701-706.

25. Dossing M, Khan J, Al-Rabiah F. Risk factors for chronic obstructive lung disease in Saudi Arabia. Respir Med 1994; 88: 519-522. 